\title{
Antiviral activity of Brincidofovir on Parvovirus B19
}

\author{
Gloria Bua ${ }^{1}$, Ilaria Conti ${ }^{1}$, Elisabetta Manaresi ${ }^{1}$, Phiroze Sethna ${ }^{2}$, Scott Foster ${ }^{2}$, \\ FRANCESCA BONVICINI ${ }^{1}$, GIORGIO GALLINELLA ${ }^{1,3 *}$ \\ ${ }^{1}$ Department of Pharmacy and Biotechnology University of Bologna, Bologna, Italy \\ ${ }^{2}$ Chimerix, Durham, North Carolina, USA
}

Running Title: Parvovirus B19 Inhibition by Brincidofovir

${ }^{*}$ Corresponding Author:

Giorgio Gallinella

University of Bologna

${ }^{1}$ Department of Pharmacy and Biotechnology

${ }^{3}$ S.Orsola-Malpighi Hospital - Microbiology

Via Massarenti, 9

I-40138 Bologna, Italy

Phone:\#39 0514290900

E-mail:giorgio.gallinella@unibo.it 


\section{Abstract}

Parvovirus B19 (B19V), a single-stranded DNA virus in the family Parvoviridae, is a human pathogenic virus responsible for a wide range of clinical manifestations. Currently there is no approved antiviral therapy for parvovirus infection. The acyclic nucleoside phosphonate cidofovir (CDV) has been demonstrated to inhibit replication of B19V in vitro. The aim of the present study was to evaluate whether brincidofovir (BCV), a novel lipid conjugate of CDV, could also inhibit B19V replication. Experiments were carried out in erythroid progenitor cells (EPCs) and UT7/EpoS1 cells, infected with B19V and cultured in the presence of different concentrations of BCV and CDV for comparison. The dynamics of viral replication was evaluated by a qPCR-based assay and the extent of inhibition of viral replication exerted by the compounds determined, along with the effect of the compounds on cell viability and cell proliferation rates. Results confirmed that BCV showed significantly higher antiviral activity against B19V compared to CDV in both cellbased systems. For $\mathrm{BCV}$, the calculated $\mathrm{EC}_{50}$ values were in the range 6.6-14.3 $\mu \mathrm{M}$ in $\mathrm{EPCs}$ and 0.22-0.63 $\mu \mathrm{M}$ in UT7/EpoS1 cells. In comparison, the $\mathrm{EC}_{50}$ values for CDV were $>300 \mu \mathrm{M}$ in EPCs and $16.1 \mu \mathrm{M}$ in UT7/EpoS1 cells. Concurrently, the effects on cell viability were observed at a much higher concentration of $\mathrm{BCV}$, with calculated $\mathrm{CC}_{50}$ values in the range 93.4-102.9 $\mu \mathrm{M}$ in EPCs and 59.9-66.8 $\mu \mathrm{M}$ in UT7/Epos1. The antiviral activity was observed specifically with the metabolically active stereoisomer of BCV suggesting that CDV-diphosphate, the metabolite of both BCV and CDV, was the active antiviral. Our results support a selective role for BCV in the inhibition of B19 viral replication.

\section{Keywords}

Parvovirus B19; brincidofovir; replication inhibition; erythroid progenitor cells, UT7/EpoS1 cells; 


\section{Introduction}

Parvovirus B19 (B19V) is a single-stranded DNA virus in the family Parvoviridae, still in need of a specific antiviral [1, 2]. The virus has a small genome, a $5.6 \mathrm{~kb}$ ssDNA molecule, with a compact organization and a relatively limited coding repertoire, comprising a non-structural protein, NS, whose function is essential for virus replication, and two structural proteins, VP1 and VP2, that form a $\mathrm{T}=1,22 \mathrm{~nm}$ icosahedral capsid. A pathogenic human virus, B19V is characterized by a selective but not exclusive tropism for erythroid progenitor cells (EPCs) in the bone marrow, and by a strict dependence on the cellular machinery and environment for its replication, so that the target cell types, their differentiation stage and proliferation rate are all critical to the diverse outcomes of infection. The virus is capable of long-term persistence in disparate tissues [3], and can establish a complex relationship with the immune system, whose efficacy in innate and adaptive responses can be critical to the course of infection and the development of pathological processes.

In the general population, infection is widespread and can be associated with a range of pathologies and clinical manifestations, from asymptomatic or mild, to severe and in some cases life-threatening, whose characteristics and outcomes depend on the interplay between the viral properties and the physiological and immune status of the infected individuals [1,2]. Cells of the erythropoietic lineage in the bone marrow constitute a primary target, but a large spectrum of secondary target tissues and organs can be involved [4]. The selective tropism for erythroid progenitor cells in the bone marrow can cause a partial block in erythropoiesis, that may manifest as transient or persistent erythroid aplasia [5]. Common systemic manifestations of infection are erythema infectiosum in children and post-infection arthropathies mainly affecting adults; moreover, the virus has been implicated in a growing collection of other different pathologies, among them myocarditis [6], connective tissue diseases and autoimmune processes [7]. Notably, infection in pregnancy may be transmitted to the fetus, posing a risk of fetal death, fetal hydrops and possible adverse perinatal outcome [8, 9].

The gap in the development of antiviral strategies directed against B19V is striking [10]. A vaccine against B19V is technically feasible, but still under development $[11,12]$, and no specific antiviral 
therapy has been investigated or clinically evaluated for B19V. Currently, treatment options are limited and generally supportive. Blood transfusions are required to overcome acute or chronic anemia, while intravenous immunoglobulin (IVIG) is considered the only available option to neutralize infectious virus and to control infection in cases of individuals with an impaired immune system [13-15]. However, the beneficial effects of supportive treatments are limited, and even IVIG treatments are seldom able to clear infection unless a patient's own antiviral immune response develops and becomes effective.

An effective antiviral would have profound implications in the treatment of hematological complications encountered during the acute or chronic phase of the infection, especially in subjects with stressed erythropoiesis or with immune system deficits, or to reduce the inflammatory or systemic aspects of infections in atypical cases, or potentially could be used for prophylaxis in selected cases.

The incomplete characterization of the viral proteome and of the molecular mechanisms involved in viral replication have hampered the rational design of specifically targeted drugs, while the demanding in vitro cell culture conditions have limited the feasibility of a high-throughput screen against available chemical libraries. To overcome these barriers, our group previously took two alternative approaches, based on a drug repositioning strategy, and on investigating known antiviral compounds for a possible activity against B19V. The first approach yielded antiviral activity provided by the cell-proliferation inhibitor hydroxyurea (HU) [16], and the second approach yielded the acyclic nucleoside phosphonate cidofovir (CDV) though with suboptimal activity $[17,18]$. The aim of the present research project was to evaluate whether brincidofovir (BCV), a novel lipid conjugate of CDV possessing enhanced antiviral activity against dsDNA viruses [19-21], also exerts an inhibitory effect against B19V replication, and in particular whether it might perform more favorably compared to CDV.

Two in vitro cellular systems established for B19V were used for this study. In vitro derived EPCs constitute a cellular population analogous to the primary target cells in the bone marrow and present full permissiveness to viral replication depending on differentiation stage and proliferation rate $[22,23]$; the human myeloblastoid cell line UT7/EpoS1 presents a restricted pattern of 
permissiveness [24, 25], allowing viral replication along with a limited yield of infectious virus production. In our study, both the EPC and UT7/EpoS1 cells were infected with B19V and then cultured for a single round of infection in the presence of test compounds, BCV and CDV for comparison. The dynamics of viral replication was evaluated by a qPCR-based assay, and the extent of inhibition of viral replication exerted by the compounds determined, along with the extent of inhibition on cell viability and cell proliferations rates. Experimental evidence indicated that BCV can be effective in inhibiting B19V replication, and demonstrated an enhanced inhibitory activity compared to CDV. 


\section{Materials and Methods}

\subsection{Chemicals}

Brincidofovir (BCV) was provided by Chimerix (Chimerix, Inc., Durham, USA). Unless stated, BCV refers to the S-enantiomer (CMX001) as opposed to the R-enantiomer (CMX029). Cidofovir (CDV) was purchased from Sigma at a purity of $>98 \%$. In all cases, dry powder was resuspended in phosphate buffered saline (PBS), $\mathrm{pH}$ 11.6, at 10mM, then aliquots of the stock solution were stored at $-70^{\circ} \mathrm{C}$ until use.

\subsection{Cells}

Erythroid progenitor cells (EPCs) were generated in vitro from peripheral blood mononuclear cells (PBMC), obtained from the leukocyte-enriched buffy coats of anonymous blood donors available for institutional research purposes from the Immunohematology and Transfusion Service, S.Orsola-Malpighi University Hospital, Bologna (http://www.aosp.bo.it/content/immunoematologiae-trasfusionale; authorization 0070755/1980/2014, issued by Head of Service). Availability was granted under conditions complying with Italian privacy law. Neither specific ethics committee approval nor written consent from donors was required for this research project. PBMC, isolated by centrifugation in Ficoll-Paque Plus (GE Healthcare Bio-Sciences AB), were cultured in IMDM (Gibco) supplemented with 20\% serum substitute BIT 9500 (StemCell Technologies), and enriched with erythropoietic growth factors as described $[23,26]$. The cells were maintained at $37^{\circ} \mathrm{C}$ in $5 \%$ $\mathrm{CO}_{2}$ and used for infection experiments at day $9 \pm 1$, when permissiveness to $\mathrm{B} 19 \mathrm{~V}$ infection is maximal. UT7/EpoS1 cells were cultured in IMDM, supplemented with $10 \%$ FCS and $2 \mathrm{U} / \mathrm{mL}$ rhu erythropoietin, at $37^{\circ} \mathrm{C}$ and $5 \% \mathrm{CO}_{2}[27]$.

\subsection{Infection}

A B19V viremic serum sample, identified in our laboratory in the course of institutional diagnostic service and available for research purposes according to Italian privacy law, was used as source of virus for the infection experiments. The viremic serum contained $10^{12} \mathrm{~B} 19 \mathrm{~V}$ (genotype 1) genome copies (geq)/mL, as determined by quantitative PCR analysis [28, 29], and tested negative by 
routine diagnostic assays to other viruses, including HIV, HBV, HCV, HSV, VZV, EBV, CMV, HHV8, AdV, BKV.

For infection, cells were incubated in PBS at a density of $10^{7}$ cell/ml, in the presence of the B19V viremic serum, diluted in PBS in order to obtain the desired multiplicity of infection (moi, expressed as geq/cell). EPCs were infected with different moi, from $10^{1} \mathrm{geq} / \mathrm{cell}$ to $10^{4} \mathrm{geq} / \mathrm{cell}$, while UT7/EpoS1 were infected with at the highest moi of $10^{4} \mathrm{geq} / \mathrm{cell}$. Following $2 \mathrm{~h}$ at $37^{\circ} \mathrm{C}$, the inoculum virus was washed twice in PBS and the cells were incubated at $37^{\circ} \mathrm{C}$ in $5 \% \mathrm{CO}_{2}$ in the respective growth medium, at the different concentrations of tested compounds, at an initial density of $10^{6}$ cells $/ \mathrm{mL}$.

\subsection{Nucleic acids purification}

Equal amounts of cell cultures, corresponding to $1.5 \times 10^{5}$ cells, were collected as appropriate at 2 or 48 hours post-infection (hpi) and processed by using the Maxwell Viral Total Nucleic Acid kit on a Maxwell MDx platform (Promega), following the manufacturer's instructions, in order to obtain a total nucleic acid fraction in elution volumes of $150 \mu \mathrm{L}$.

\subsection{Quantitative real-time PCR}

For quantitative analysis of viral DNA, an aliquot of the eluted nucleic acids, corresponding to $\sim 500$ cells, was amplified by qPCR using the primer pair R2210-R2355, located in the central exon of B19V genome [23-25], and quantified using an external calibration curve, in a RotorQ system (Qiagen). As a control, a target sequence in the region of genomic DNA coding for 5.8S rRNA (rDNA) was amplified in parallel reactions. Amplification reactions were performed by using Maxima SYBR Green qPCR Master Mix (Thermo Scientific), including primers (obtained from Eurofins Genomics) at a final concentrations of $0.3 \mu \mathrm{M}$. Quantitation of viral DNA was obtained by the absolute quantitation algorithm, converting quantification cycle $(\mathrm{Cq})$ values to geq number using external calibration curves obtained from standard targets. For the rDNA target, a coefficient of variation of quantification cycle values for the different samples $\leq 5 \%$ was required, so that this parameter could be considered invariant and the normalization by rDNA not necessary for the following quantitative determination of viral targets. 


\subsection{Fluorescent In Situ Hybridization (FISH) Assay}

Aliquots of cell cultures were processed by on slide FISH assay for the detection of viral nucleic acids, as described [30] with minor modifications. Cells were spotted on glass slides, fixed in PBSparaformaldehyde $0.5 \%$ at $4^{\circ} \mathrm{C}$ for $30 \mathrm{~min}$ and permeabilized for $45 \mathrm{~min}$ in PBS-saponin $0.2 \%$. Hybridization reaction was carried out in $25 \mu$ l of a hybridization solution containing $25 \mathrm{ng}$ of a digoxigenin labeled, random-primed full-length genomic probe (Dig High Prime, Roche). Specimens and hybridization mixture were denatured together by heating at $95^{\circ} \mathrm{C}$ for 5 min and then incubated at $37^{\circ} \mathrm{C}$ for $12 \mathrm{~h}$. Following hybridization, the slides were washed twice at $37^{\circ} \mathrm{C}$ with $50 \%$ formamide $-2 \times \mathrm{SSC}(300 \mathrm{mM} \mathrm{NaCl}, 30 \mathrm{mM}$ sodium citrate, $\mathrm{pH} 7.0)$ buffer and twice at room temperature in $2 \times S S C$ buffer, 10 minutes each. Detection of the hybrids was performed with a FITC-conjugate anti-digoxigenin antibody (Roche) diluted 1:20 in PBS-BSA 1\% and incubated for 1 $\mathrm{h}$; after washing in PBS, slides were stained with Evans blue and observed on a fluorescence microscopy (EX 450-490 nm, BA $520 \mathrm{~nm}$ ).

\subsection{Cell viability and proliferation assays}

The effects of tested compounds on cell viability and proliferation were monitored by a WST-8 based assay, a water-soluble salt reagent that produces a formazan dye upon reduction in response to metabolic activity (CCK8 assay, Dojindo Molecular Technologies), and by evaluation of 5-bromo-2'-deoxyuridine (BrdU) incorporation into newly synthesized DNA (Cell proliferation ELISA BrdU Assay, Roche Diagnostics), following established and optimized protocols [16]. For experiments, $5 \times 10^{4}$ cells were seeded in $100 \mu \mathrm{L}$ volumes in a 96-well culture microplate, and cultured in the absence, as control, or in the presence of different concentration of compounds added to medium for 48 hours, paralleling the time course of infection. For the cell viability assay, WST-8 reagent was added for the last 6 hours for EPCs, or 2 hours for UT7/EpoS1. For the cell proliferation assay, of BrdU at $10 \mu \mathrm{M}$ was added for the last 24 hours for both cell types. The amounts of formazan dye and of incorporated BrdU were measured as absorbance (OD) values according to manufacturers' instructions. Replicate net OD values were normalized with respect to the control samples and expressed as mean percentage values for, respectively, cell viability and proliferation. 


\subsection{Statistical analysis}

Experiments were carried out in duplicate (or more) series unless stated and, for each sample, quantitative determinations were carried out in duplicate (or more) values. Statistical analysis was carried out using GraphPad Prism version 5.00 for Windows (GraphPad Software, San Diego California, USA). Two-way ANOVA (analysis of variance) followed by the Bonferroni test was used to compare data obtained in different experimental conditions. Linear regression analysis was carried out to correlate input moi values and calculated amounts of viral nucleic acids. $\mathrm{EC}_{50}$ and $\mathrm{CC}_{50}$ values (mean and 95\% C.I.) for the different experimental series were determined by nonlinear regression analysis on percentage residual viral replicative activity and/or cell viability or proliferation, for each different tested concentration of compounds relative to control samples. 


\section{Results}

\subsection{Effect of BCV and CDV on B19V replication}

As a first set of experiments, a comparative investigation of the ability of BCV as compared to CDV to inhibit B19V replication in both EPCs and UT7/EpoS1 cell systems was carried out. PBMC derived, in vitro differentiated EPCs and UT7/EpoS1 cells were infected with B19V at a moi of $10^{4}$ geq/cell. Following incubation to allow attachment and penetration of virus ( 2 hpi samples), infected cells were divided and cultured in the absence, as a control, and in the presence of different concentrations of $\mathrm{BCV}$ or $\mathrm{CDV}$, in the range $0.1-500 \mu \mathrm{M}$, for a complete course of infection (48 hpi samples). Equivalent cell fractions were collected at $2 \mathrm{hpi}$ and at $48 \mathrm{hpi}$ for the different conditions, and quantitative determination of viral DNA to determine viral replicative activity, and of cellular rDNA for control and normalization, was carried out by qPCR.

The extent of viral replication, measured as the variation in viral DNA detected after a course of infection, varied in function of the cell type, the compound, and the concentration of compounds added to infected cell cultures (Figure 1). By 2-way ANOVA, all variables as well as their interaction contributed significantly as a source of variation to the observed effects (at $p<0.001)$, as the cell/compound combination accounted for $18.7 \%$ of total variance, compound concentration for $39.2 \%$, and interaction of variables for $20.2 \%$. The amount of DNA measured from 2 to $48 \mathrm{hpi}$ in control samples increased on average $1.1 \pm 0.1 \mathrm{Log}$, indicating productive viral replication. For all cell/compound combination series, increasing the concentration of compounds progressively decreased the amount of viral DNA detected at $48 \mathrm{hpi}$, thus indicating an inhibitory effect of the compounds on the extent of viral replication. Complete inhibition, as indicated by a significant (at $\mathrm{p}<0.01)$ net reduction in the amount of viral DNA from 2 hpi to $48 \mathrm{hpi}$, could be observed: for BCV, -0.6 Log at $\geq 500 \mu \mathrm{M}$ in EPCs and -0.5 Log at $\geq 10 \mu \mathrm{M}$ in UT7/EpoS1; for CDV, not in the tested range in EPCs and -0.7 Log at $\geq 500 \mu \mathrm{M}$ in UT7/EpoS1. At $48 \mathrm{hpi}$, the observed variations compared to the respective control samples were: for BCV, -1.7 Log at $\geq 500 \mu \mathrm{M}$ in EPCs and -1.7 Log at $\geq 10 \mu \mathrm{M}$ in UT7/EpoS1; for CDV, -0.5 Log at at $\geq 500 \mu \mathrm{M}$ in EPCs and -0.7 Log at $\geq 500 \mu \mathrm{M}$ in UT7/EpoS1. 
The inhibitory effects of BCV and CDV on B19V replication were also assessed by FISH analysis

(Figure 2). FISH-positive cells, corresponding to permissive cells actually supporting B19V replication within a restrictive cell population, were evident as clearly stained above a low intensity Evans blue counterstain, and showed a localized, mainly nuclear, distribution of target. Although qualitative, this result is consistent with qPCR assay data (Figure 1), confirming that productively infected cells could not be detected where BCV or CDV concentrations were sufficient to completely inhibit B19V replication.

Thus, experimental data obtained from both $\mathrm{qPCR}$ and FISH assays confirmed that BCV is effective against B19V, and proved that BCV was a much more potent inhibitor of B19V replication in both EPCs and UT7/EpoS1 cell systems. In particular, in EPCs, only BCV but not CDV led to a complete inhibition of viral replication, although only at the highest concentration tested.

\subsection{Enhanced antiviral activity of BCV in EPCs}

To further characterize the antiviral activity of BCV, in vitro differentiated EPCs were infected with B19V at different multiplicities of infection (moi), in the range of $10^{1}-10^{4} \mathrm{geq} / \mathrm{cell}$, and cultured in the absence and presence of different concentrations of BCV $(0.1-500 \mu \mathrm{M})$. The extent of viral replication in the different experimental conditions was then assessed by qPCR analysis according to the previous experimental scheme.

The amount of viral DNA detected after a course of infection varied as a function of both the moi used and the concentration of BCV added to infected cell cultures. Amounts of viral DNA were plotted as a function of the moi used, for samples series collected at $2 \mathrm{hpi}$ and at $48 \mathrm{hpi}$ for all the different concentrations of BCV added to infected cell cultures (Figure 3). For any given moi and $\mathrm{BCV}$ concentration, the extent of viral replicative activity resulted in a different increase in the amount of viral DNA from $2 \mathrm{hpi}$ to $48 \mathrm{hpi}$, excepting for the highest BCV concentration. Linear regression analysis showed a good correlation between calculated amounts of viral DNA and the moi used, for all sample series in the whole test range $\left(R^{2}\right.$ in the range $\left.0.91-0.98\right)$. The linear correlation evident for the 2 hpi sample series indicated that virus attachment and penetration was driven by concentration of virus. For the different 48 hpi sample series, with BCV at concentrations 
$\leq 100 \mu \mathrm{M}$, the slopes of regression curves were statistically equivalent $(p=0.12)$, thus indicating a constant relative biological activity of $\mathrm{B} 19 \mathrm{~V}$ within the EPC cell system independent of the moi used. The shift observed in the regression curves showed statistically significant differences $(p<0.0001)$, with decrements that might be attributed to the progressive inhibitory effects of BCV on viral DNA replication. For the 48 hpi sample series, with $B C V$ at $500 \mu \mathrm{M}$, the slope of the regression curve was different from the other $48 \mathrm{hpi}$ samples and similar to the $2 \mathrm{hpi}$ sample series $(p=0.88)$, and in addition the shift of the curve was lower $(p<0.0001)$ than the 2 hpi sample series. We believe that this suggests both a block in cell proliferation and a complete inhibition of viral replication at this high $\mathrm{BCV}$ concentration.

Based on these linear relationships, the inhibitory effect of BCV on B19V replication for any given moi could be expressed and quantified as a dose-dependent reduction in the amount of viral DNA detected at $48 \mathrm{hpi}$. By expressing a normalized dose-dependent relationship between BCV concentration and percentage replicative activity with respect to the control (Figure 4), non-linear regression curve allowed determining $\mathrm{EC}_{50}$ values for $\mathrm{BCV}$ for all the different moi tested. Values in this experiment ranged between $6.6-11.5 \mu \mathrm{M}$ for the different moi used, yielding a value of $9.35 \mu \mathrm{M}$ [C.I. $8.84-9.89, R^{2}$ 0.99] for the pooled data. Activity of BCV and CDV were compared at a moi of $10^{4} \mathrm{geq} / \mathrm{cell}$; the calculated $\mathrm{EC}_{50}$ values were: for BCV, $9.65 \mu \mathrm{M}$ [C.I. $9.15-10.20, \mathrm{R}^{2}$ 0.99]; for CDV, $320.5 \mu \mathrm{M}$ [C.I. $173.9-590.7, \mathrm{R}^{2}$ 0.41] (Figure 5).

In parallel, non-linear regression was performed to determine $\mathrm{CC}_{50}$ values for cell viability (Figure 6) and proliferation (Figure 7). Regarding cell viability, calculated $\mathrm{CC}_{50}$ values were: for $\mathrm{BCV}$, $102.9 \mu \mathrm{M}$ [C.I. 87.6 - 120.8, R² 0.93]; for CDV, >500 $\mu \mathrm{M}$. Regarding cell proliferation, calculated $\mathrm{CC}_{50}$ values were: for BCV, $121.6 \mu \mathrm{M}$ [C.I. 91.7 - 161.3, R² 0.89]; for CDV, >500 $\mu \mathrm{M}$. Comparing antiviral effects (data from Figure 4) and effects on cell viability and cell proliferation (data from Figures 5 and 6 ), BCV yielded selectivity indexes (SI) values of 11.0 and 13.0 for viability and cell proliferation respectively.

\subsection{Enhanced antiviral activity of BCV in UT7/EpoS1}


The inhibition of B19V replication by BCV in UT7/EpoS1 cells was more pronounced than in EPCs. For an accurate characterization of the antiviral activity of BCV under conditions of high viral load, UT7/EpoS1 cells were infected with B19V at the moi of $10^{4} \mathrm{geq} /$ cell in the presence of $0.01-10$ $\mu \mathrm{M}$ BCV, or $0.1-500 \mu \mathrm{M}$ CDV under the same experimental scheme that were used for EPCs. A dose-dependent progressive reduction in the amount of viral DNA detected at $48 \mathrm{hpi} \mathrm{samples}$ could be observed for both BCV and CDV. Non-linear regression curve analysis allowed determining $\mathrm{EC}_{50}$ value of $0.22 \mu \mathrm{M}$ [C.I. $0.19-0.25, \mathrm{R}^{2}$ 0.99] for $\mathrm{BCV}$, and $16.1 \mu \mathrm{M}$ [C.I. 12.9 20.2, $\mathrm{R}^{2}$ 0.95] for CDV (Figure 5).

In parallel, non-linear regression was performed to determine $\mathrm{CC}_{50}$ values for cell viability (Figure 6) and proliferation (Figure 7). Regarding cell viability, calculated $\mathrm{CC}_{50}$ values were: for $\mathrm{BCV}, 66.8$ $\mu \mathrm{M}$ [C.I. 62.0 - 72.9, $\mathrm{R}^{2}$ 0.98]; for $\mathrm{CDV},>500 \mu \mathrm{M}$. Regarding cell proliferation, calculated $\mathrm{CC}_{50}$ values were: for $\mathrm{BCV}, 6.9 \mu \mathrm{M}$ [C.I. $5.7-8.4, \mathrm{R}^{2}$ 0.97]; for CDV, >500 $\mu \mathrm{M}$. Comparing antiviral potency (data from Figure 4) and effects on cell viability and cell proliferation (data from Figures 5 and 6), BCV yielded selectivity indexes (SI) values of 303.6 and 31.5 , respectively.

\subsection{Enantiomer-specific antiviral activity in EPCs and UT7/EpoS1}

To confirm that the observed inhibitory effects on the virus were specifically exerted by the metabolite, CDV-PP, the activity of the functional stereoisomer of BCV, BCV (S), was compared with that of its cognate enantiomer BCV (R). The latter is not converted to CDV-PP within cells. Infection was carried out following the established experimental scheme with both enantiomers tested in the range of $0.01-100 \mu \mathrm{M}$ in both EPCs and UT7/EpoS1 cell systems. For each sample series, the amounts of viral DNA were assessed by $\mathrm{qPCR}$ and $\mathrm{EC}_{50}$ values calculated as described previously (Figure 8). Cell viability was assessed in the same assay format by a WST-8 based assay and cytotoxicity $\mathrm{CC}_{50}$ values determined (Figure 9).

For this experimental series, calculated $\mathrm{EC}_{50}$ and $\mathrm{CC}_{50}$ values for both EPCs and UT7/EpoS1 cell systems are reported in Table 1. In EPCs, the SI values (S.I.: $\left.\mathrm{EC}_{50} / \mathrm{CCK} \mathrm{CC}_{50}\right)$ for $\mathrm{BCV}(\mathrm{S})$ and $\mathrm{BCV}(\mathrm{R})$ were 6.5 and 1.6 respectively, yielding an S/R ratio of 4.0. In UT7/EpoS1, SI values were 95.1 and 1.3 , yielding an S/R ratio of 73.2. Altogether, experimental data indicated that the 
inhibitory activity on B19V replication was exerted by the active enantiomer, BCV (S), to a significantly higher extent with respect to its cognate enantiomer BCV (R); the observed differences in selectivity indexes and $S / R$ activity ratios were dependent on the cellular environment. 


\section{Discussion}

The present study was conducted with the aim of closing the gap in the development of an antiviral strategy against B19V, a virus commonly distributed in the population, and responsible for a wide spectrum of clinical manifestations. In the absence of a vaccine to prevent infection and an effective antiviral therapy, treatment of B19V infections remains limited to supportive and nonspecific (e.g., IVIG) interventions [1, 2]. Therefore, we believe that the efforts in research and development of antiviral drugs with potent inhibitory activity against B19V should be considered of utmost importance so as to increase the available options for specific therapeutic and/or preventive treatments.

We have previously shown that CDV, an antiviral with a broad spectrum in vitro activity but with limited clinical effectiveness, inhibits B19V replication in vitro $[17,18]$. This was the first reported evidence of activity of an antiviral compound against B19V, and at the same time an expansion of the antiviral range of CDV to encompass a ssDNA virus in addition to the more widely recognized activity against dsDNA viruses. The present set of experiments investigated the activity of the lipid conjugate of CDV, BCV, to assess its potential as an antiviral agent against B19V. BCV has been shown to be more potent than CDV against dsDNA viruses [19-21] and its administration has been shown to be safe, well-tolerated and to produce a low circulating plasma concentration of CDV [31], which greatly reduces the nephrotoxicity associated with intravenous CDV administration [32]. Our experiments demonstrate that $\mathrm{BCV}$, compared to CDV, exerts an enhanced inhibitory effect on replication of the ssDNA virus B19V. This is evident in both the EPC and UT7/EpoS1 cell system even at the highest multiplicities of infection tested, with a distinct dose-dependent reduction in the amount of viral DNA synthesized. This inhibitory activity was achieved at relatively lower compound concentrations in UT7/EpoS1 than in EPCs. In addition, in the EPC cells only BCV, and not CDV, yielded a significant $\mathrm{EC}_{50}$ value and achieved complete inhibition of viral replication. Accordingly, the effects of BCV on cell viability and proliferation were measurable at lower concentrations compared to CDV in both cellular systems. The effect on cell proliferation were 
more pronounced than those on cell viability, nevertheless a favorable selectivity index for their antiviral effect was demonstrated in both assay systems.

There are two enantiomeric forms of $B C V,(S)$ and $(R)$, but only $B C V(S)$ is the active enantiomer. $\mathrm{BCV}(\mathrm{S})$ utilizes the natural lipid uptake pathway in cells that results in its rapid uptake, consequent increase in the active antiviral, CDV-PP, and hence an increase in antiviral potency [21, 31]. On the other hand, CDV-PP is undetectable in cells treated with the R-enantiomer [33]. We demonstrated here that the inhibition of viral replication is restricted to the S-enantiomer of BCV, thus supporting the hypothesis of an active and specific antiviral role of CDV-PP derived from BCV rather than an inhibition of viral replication related to a general, nonspecific cytotoxic effect.

The antiviral activity of BCV and CDV is directly correlated to CDV-diphosphate (CDV-PP) which acts as an alternate substrate for viral DNA synthesis [34, 35]. Both BCV and CDV have been reported to possess antiviral activity also against DNA viruses that do not encode their own polymerases [36-38], however in these cases the exact mechanism of inhibition has not been yet established. Possible mechanism could include the replication complex of these viruses being more conducive to incorporating CDV into viral DNA causing chain termination or impeding template activity, a decreased ability of the replication complex to excise incorporated CDV, or the possibility of inhibiting helicase activity, as encoded by LT in case of the polyomaviruses and E1 in the case of papillomaviruses $[39,40]$. It should be noted that the B19V genome replicative intermediates are actually dsDNA forms that utilize the host replication machinery and metabolic environment, so the mechanisms of inhibition could also probably be similar to what is proposed for other dsDNA virus that do not encode their own DNA polymerase.

Replication of B19V in vitro is limited by a highly restrictive cellular environment, so that even at the high multiplicity of infection of $10^{4}$, only a minor fraction of cells can support viral replication (Figure 2) [30]. As a result, a relatively low ( 1-2 Log) increase in the amount of viral DNA in the course of infection from 2 to $48 \mathrm{hpi}$ is normally achieved (Figures 1,3). Although this can be considered suboptimal, the data obtained allowed discrimination of the activities of the different compounds tested and calculation of the different $\mathrm{EC}_{50}$ values in different cellular environments. EPCs and UT7/EpoS1 cell systems possess different properties that are to be taken into consideration when 
considering our experimental results. EPCs are primary cells with a limited lifespan, and represent a cellular system more closely resembling the natural target cells within bone marrow environment [41]. Circulating EPCs can be selectively induced to proliferate and differentiate along the erythroid lineage, progressively acquiring sensitivity to viral infection and full permissiveness to viral replication, in particular at a stage corresponding to the proerythroblast differentiation stage in the bone marrow [23]. However, EPCs are cultured in conditions that approximate the conditions of the bone marrow environment, and constitute a population with heterogeneous characteristics related to the differentiation stage, proliferation rate and metabolic activity. The effective inhibitory activity of BCV observed in these cells is of crucial relevance, especially in comparison to the limited activity shown by CDV. The inherent heterogeneity and a slow overall metabolic rate of EPCs may hinder the accurate evaluation of the antiviral potency of BCV, as the conversion of BCV to the active antiviral CDV-PP is expected to be more pronounced in metabolically active cells, and hence the lower potency in EPCs observed in our experiments. On the other hand, UT7/EpoS1, a cell line of myeloblastoid origin, is the most permissive and commonly used cellular line when investigating B19V [27]. In these cells, active viral replication is shown to occur only in a subset of cells $[30,42]$, but at the population level the degree of replication of viral DNA shows relative increases comparable to the fully permissive EPCs $[24,25]$. Thus, UT7/EpoS1 may constitute a more suitable and appropriate experimental system, for evaluating the activity of BCV against $\mathrm{B} 19 \mathrm{~V}$. We report here that the $\mathrm{EC}_{50}$ against $\mathrm{B} 19 \mathrm{~V}$ is in the same order of magnitude as compared to those determined for other dsDNA viruses, and more importantly, within the range of concentrations achieved with clinically relevant doses [21, 31].

B19V is highly dependent on cellular machinery for its lifecycle $[43,44]$ and offers few virus specific antiviral targets, but the observed capacity of broad spectrum antiviral compounds to interfere with its biological activity indicates the presence of pathways susceptible to potential inhibition in a complex and as yet not fully characterized virus-cell interaction network. We believe that the differences observed within the two cellular systems may reflect differences in the permeability of cells to the compounds, the overall metabolic rate of the cellular environment, or to different mechanisms of interference with the normal metabolism of nucleotides. Hence, in the present set 
of experiments, the observed lower efficacy of BCV in EPCs than in UT7/EpoS1 may reflect the low metabolic rate in these cells as playing an important role in the higher EC50 scored in our assays. Further experiments will be required to evaluate the kinetics of CDV-PP formation within the cells, whether the actual intracellular concentration of compounds effectively correlate with the antiviral activity, and if activity can be enhanced by an extended exposure of cells to non-toxic concentrations of drugs. The recent development of a reverse genetic system for B19V [45] will also provide a valuable tool to investigate in more detail the targets and mechanisms of activity of compounds in the observed inhibition of viral replication.

In conclusion, we demonstrate that the investigational compound, BCV, effectively inhibits B19V with highly favorable properties in terms of in vitro activity and selectivity, thus expanding its antiviral spectrum to encompass an ssDNA virus and establishing its potential as a B19V antiviral agent. Further progress in our knowledge of the biological characteristics of B19V and of its interaction with the cellular environment will lead to a better understanding of the viral target/s and mechanism/s appropriate for the continued development of an antiviral strategy directed against the human pathogenic virus B19V. 


\section{Acknowledgments and Funding}

This research was partly supported from Chimerix as objective of a cooperation agreement between Chimerix and the Department of Pharmacy and Biotechnology of the University of Bologna. This research was also supported by block grants from the University of Bologna (RFO 2014-2016 to G.G.). 


\section{References}

1. Gallinella G. Parvovirus B19 Achievements and Challenges. ISRN Virology (2013):10.5402/2013/898730.

2. Qiu J, Soderlund-Venermo M, Young NS. Human Parvoviruses. Clin Microbiol Rev (2017) 30:43-113.

3. Bua G, Gallinella G. How does parvovirus B19 DNA achieve lifelong persistence in human cells? Future Virol (2017) 12:549-553.

4. Adamson-Small LA, Ignatovich IV, Laemmerhirt MG, Hobbs JA. Persistent parvovirus B19 infection in non-erythroid tissues: possible role in the inflammatory and disease process. Virus Res (2014) 190:8-16.

5. Kerr JR. A review of blood diseases and cytopenias associated with human parvovirus B19 infection. Rev Med Virol (2015) 25:224-40.

6. Verdonschot J, Hazebroek M, Merken J, Debing Y, Dennert R, Brunner-La Rocca HP, Heymans S. Relevance of cardiac parvovirus B19 in myocarditis and dilated cardiomyopathy: review of the literature. Eur J Heart Fail (2016) 18:1430-1441.

7. Kerr JR. The role of parvovirus B19 in the pathogenesis of autoimmunity and autoimmune disease. J Clin Pathol (2016) 69:279-91.

8. Bonvicini F, Bua G, Gallinella G. Parvovirus B19 infection in pregnancy-awareness and opportunities. Curr Opin Virol (2017) 27:8-14.

9. Bascietto F, Liberati M, Murgano D, Buca D, lacovelli A, Flacco ME, Manzoli L, Familiari A, Scambia G, D'Antonio F. Outcomes associated with fetal Parvovirus B19 infection: A systematic review and meta-analysis. Ultrasound Obstet Gynecol (2018).

10. De Clercq E, Li G. Approved Antiviral Drugs over the Past 50 Years. Clin Microbiol Rev (2016) 29:695-747.

11. Chandramouli S, Medina-Selby A, Coit D, Schaefer M, Spencer T, Brito LA, Zhang P, Otten G, Mandl CW, Mason PW, Dormitzer PR, Settembre EC. Generation of a parvovirus B19 vaccine candidate. Vaccine (2013) 31:3872-8.

12. Penkert RR, Young NS, Surman SL, Sealy RE, Rosch J, Dormitzer PR, Settembre EC, Chandramouli S, Wong S, Hankins JS, Hurwitz JL. Saccharomyces cerevisiae-derived virus-like particle parvovirus B19 vaccine elicits binding and neutralizing antibodies in a mouse model for sickle cell disease. Vaccine (2017) 35:3615-3620.

13. Mouthon L, Lortholary O. Intravenous immunoglobulins in infectious diseases: where do we stand? Clin Microbiol Infect (2003) 9:333-8.

14. Crabol Y, Terrier B, Rozenberg F, Pestre V, Legendre C, Hermine O, MontagnierPetrissans C, Guillevin L, Mouthon L, Groupe d'experts de l'Assistance Publique-Hopitaux de P. Intravenous immunoglobulin therapy for pure red cell aplasia related to human parvovirus b19 infection: a retrospective study of 10 patients and review of the literature. Clin Infect Dis (2013) 56:968-77.

15. Mouthon L, Michel M, Gandre C, Montagnier-Petrissans C, Chevreul K. Costs of intravenous immunoglobulin therapy in patients with unconfirmed parvovirus b19 pure red cell aplasia. Clin Infect Dis (2015) 60:488.

16. Bonvicini F, Bua G, Conti I, Manaresi E, Gallinella G. Hydroxyurea inhibits parvovirus B19 replication in erythroid progenitor cells. Biochem Pharmacol (2017) 136:32-39.

17. Bonvicini F, Bua G, Manaresi E, Gallinella G. Antiviral effect of cidofovir on parvovirus B19 replication. Antiviral Res (2015) 113:11-8.

18. Bonvicini F, Bua G, Manaresi E, Gallinella G. Enhanced inhibition of parvovirus B19 replication by cidofovir in extendedly exposed erythroid progenitor cells. Virus Res (2016) 220:47-51.

19. Aldern KA, Ciesla SL, Winegarden KL, Hostetler KY. Increased antiviral activity of 1-Ohexadecyloxypropyl-[2-(14)C]cidofovir in MRC-5 human lung fibroblasts is explained by unique cellular uptake and metabolism. Mol Pharmacol (2003) 63:678-81. 
20. Williams-Aziz SL, Hartline CB, Harden EA, Daily SL, Prichard MN, Kushner NL, Beadle JR, Wan WB, Hostetler KY, Kern ER. Comparative activities of lipid esters of cidofovir and cyclic cidofovir against replication of herpesviruses in vitro. Antimicrob Agents Chemother (2005) 49:3724-33.

21. Hostetler KY. Alkoxyalkyl prodrugs of acyclic nucleoside phosphonates enhance oral antiviral activity and reduce toxicity: current state of the art. Antiviral Res (2009) 82:A84-98.

22. Wong S, Zhi N, Filippone C, Keyvanfar K, Kajigaya S, Brown KE, Young NS. Ex vivogenerated CD36+ erythroid progenitors are highly permissive to human parvovirus B19 replication. J Virol (2008) 82:2470-6.

23. Bua G, Manaresi E, Bonvicini F, Gallinella G. Parvovirus B19 Replication and Expression in Differentiating Erythroid Progenitor Cells. PLoS One (2016) 11:e0148547.

24. Bonvicini F, Filippone C, Delbarba S, Manaresi E, Zerbini M, Musiani M, Gallinella G. Parvovirus B19 genome as a single, two-state replicative and transcriptional unit. Virology (2006) 347:447-54.

25. Bonvicini F, Filippone C, Manaresi E, Zerbini M, Musiani M, Gallinella G. Functional analysis and quantitative determination of the expression profile of human parvovirus B19. Virology (2008) 381:168-77.

26. Filippone C, Franssila R, Kumar A, Saikko L, Kovanen PE, Soderlund-Venermo M, Hedman K. Erythroid progenitor cells expanded from peripheral blood without mobilization or preselection: molecular characteristics and functional competence. PLoS One (2010) 5:e9496.

27. Wong S, Brown KE. Development of an improved method of detection of infectious parvovirus B19. J Clin Virol (2006) 35:407-13.

28. Gallinella G, Bonvicini F, Filippone C, Delbarba S, Manaresi E, Zerbini M, Musiani M. Calibrated real-time PCR for evaluation of parvovirus B19 viral load. Clin Chem (2004) 50:759-62.

29. Bonvicini F, Manaresi E, Bua G, Venturoli S, Gallinella G. Keeping pace with parvovirus B19 genetic variability: a multiplex genotype-specific quantitative PCR assay. J Clin Microbiol (2013) 51:3753-9.

30. Manaresi E, Bua G, Bonvicini F, Gallinella G. A flow-FISH assay for the quantitative analysis of parvovirus B19 infected cells. J Virol Methods (2015) 223:50-4.

31. Painter W, Robertson A, Trost LC, Godkin S, Lampert B, Painter G. First pharmacokinetic and safety study in humans of the novel lipid antiviral conjugate CMX001, a broadspectrum oral drug active against double-stranded DNA viruses. Antimicrob Agents Chemother (2012) 56:2726-34.

32. Tippin TK, Morrison ME, Brundage TM, Mommeja-Marin H. Brincidofovir Is Not a Substrate for the Human Organic Anion Transporter 1: A Mechanistic Explanation for the Lack of Nephrotoxicity Observed in Clinical Studies. Ther Drug Monit (2016) 38:777-786.

33. McMullan LK, Flint M, Dyall J, Albarino C, Olinger GG, Foster S, Sethna P, Hensley LE, Nichol ST, Lanier ER, Spiropoulou CF. The lipid moiety of brincidofovir is required for in vitro antiviral activity against Ebola virus. Antiviral Res (2016) 125:71-8.

34. De Clercq E, Holy A. Acyclic nucleoside phosphonates: a key class of antiviral drugs. Nat Rev Drug Discov (2005) 4:928-40.

35. Magee WC, Evans DH. The antiviral activity and mechanism of action of (S)-[3-hydroxy-2(phosphonomethoxy)propyl] (HPMP) nucleosides. Antiviral Res (2012) 96:169-80.

36. Johnson JA, Gangemi JD. Selective inhibition of human papillomavirus-induced cell proliferation by (S)-1-[3-hydroxy-2-(phosphonylmethoxy)propyl]cytosine. Antimicrob Agents Chemother (1999) 43:1198-205.

37. Randhawa P, Farasati NA, Shapiro R, Hostetler KY. Ether lipid ester derivatives of cidofovir inhibit polyomavirus BK replication in vitro. Antimicrob Agents Chemother (2006) 50:15646.

38. Jiang ZG, Cohen J, Marshall LJ, Major EO. Hexadecyloxypropyl-cidofovir (CMX001) suppresses JC virus replication in human fetal brain SVG cell cultures. Antimicrob Agents Chemother (2010) 54:4723-32. 
39. Andrei G, Topalis D, De Schutter T, Snoeck R. Insights into the mechanism of action of cidofovir and other acyclic nucleoside phosphonates against polyoma- and papillomaviruses and non-viral induced neoplasia. Antiviral Res (2015) 114:21-46.

40. Tsang SH, Wang R, Nakamaru-Ogiso E, Knight SA, Buck CB, You J. The Oncogenic Small Tumor Antigen of Merkel Cell Polyomavirus Is an Iron-Sulfur Cluster Protein That Enhances Viral DNA Replication. J Virol (2016) 90:1544-56.

41. Merryweather-Clarke AT, Atzberger A, Soneji S, Gray N, Clark K, Waugh C, McGowan SJ, Taylor S, Nandi AK, Wood WG, Roberts DJ, Higgs DR, Buckle VJ, Robson KJ. Global gene expression analysis of human erythroid progenitors. Blood (2011) 117:e96-108.

42. Bonvicini F, Mirasoli M, Manaresi E, Bua G, Calabria D, Roda A, Gallinella G. Single-cell chemiluminescence imaging of parvovirus B19 life cycle. Virus Res (2013) 178:517-21.

43. Luo Y, Qiu J. Human parvovirus B19: a mechanistic overview of infection and DNA replication. Future Virol (2015) 10:155-167.

44. Ganaie SS, Qiu J. Recent Advances in Replication and Infection of Human Parvovirus B19. Front Cell Infect Microbiol (2018) 8:166.

45. Manaresi E, Conti I, Bua G, Bonvicini F, Gallinella G. A Parvovirus B19 synthetic genome: sequence features and functional competence. Virology (2017) 508:54-62. 


\section{Figure Legends}

\section{Figure 1. Inhibition of B19V by BCV and CDV, in EPCs and UT7/EpoS1 cells.}

The amounts of B19V DNA were determined by qPCR, at $2 \mathrm{hpi}$ and $48 \mathrm{hpi}$, at the different BCV or CDV concentrations, and expressed as Log B19V DNA geq/1000 cells. Histograms indicate mean values \pm standard error of means obtained from 3 (for EPCs) or 5 (for UT7/EpoS1) independent experiments. Analysis of variances were followed by Bonferroni post-comparison test to indicate a significant reduction in $\mathrm{B} 19 \mathrm{~V}$ replication at $48 \mathrm{hpi}$ compared to the respective $2 \mathrm{hpi}$ samples (dashed lines, ${ }^{* *} p<0.01$ ).

\section{Figure 2. FISH assay for the detection of viral nucleic acids.}

EPCs (A, B) and UT7/EpoS1 (C, D) were infected with B19V at the moi of $10^{4} \mathrm{geq} / \mathrm{cell}$, then cultured for a 48 hour time course of infection in the presence of BCV $(A, C)$ or CDV $(B, D)$ at 0.0 (as control), 10, $500 \mu \mathrm{M}$ (columns 1, 2, 3). Cells were analyzed by FISH assay for the detection of B19V nucleic acids. A whole length genomic probe for B19V, digoxigenin-labelled, was used and hybrids detected by anti-DIG Fab, FITC conjugated. Where present, positive cells are clearly stained above a low intensity background and show a localized, mainly nuclear, distribution of target, indicating productively infected cells (insets).

Figure 3. B19V DNA in EPCs, as a function of moi and BCV concentration.

Amounts of viral DNA (Log B19V DNA geq/1000 cells ) plotted as a function of the Log of moi used $\left(10^{1}-10^{4}\right)$, for samples series collected at $2 \mathrm{hpi}$ and at $48 \mathrm{hpi}$ for all the different concentrations of BCV added to infected EPCs cell cultures Values are mean of duplicate independent experiments and bars indicate the standard error of means. Lines are linear regression analysis for the respective sample series $\left(R^{2} 0.91-0.98\right)$. 
Figure 4. Viral replication, normalized response curve to BCV in B19V infected EPCs Normalized dose-response curve, calculated from qPCR data obtained at $48 \mathrm{hpi}$ for the different experimental series (B19V in EPCs, moi 101-104). Log B19V DNA as a function of BCV concentration, expressed as percentage replication compared to control samples. $\mathrm{EC}_{50}$ values derived from this plot are reported in the text.

Figure 5. Viral replication, normalized response to BCV and CDV in EPCs and UT7/EpoS1. Normalized dose-response curve, calculated from qPCR data obtained at $48 \mathrm{hpi}$ for the different experimental series (B19V in EPCs and UT7/EpoS1). Log B19V DNA as a function of BCV or CDV concentration, expressed as percentage replication compared to control samples. $\mathrm{EC}_{50}$ values derived from this plot are reported in the text.

Figure 6. Cell viability, normalized response to BCV and CDV in EPCs and UT7/EpoS1. Normalized dose-response curve, calculated from CCK8 assay data obtained at 48 hpi for the different experimental series (B19V in EPCs and UT7/EpoS1). Cell viability as a function of BCV or CDV concentration, expressed as percentage value compared to control samples. $\mathrm{CC}_{50}$ values derived from this plot are reported in the text.

Figure 7. Cell proliferation, normalized response to BCV and CDV in EPCs and UT7/EpoS1. Normalized dose-response curve, calculated from BrdU incorporation assay data obtained at 48 hpi for the different experimental series (B19V in EPCs and UT7/EpoS1). Cell proliferation as a function of BCV or CDV concentration, expressed as percentage value compared to control samples. $\mathrm{CC}_{50}$ values derived from this plot are reported in the text.

Figure 8. Viral replication, normalized response to BCV (S) and BCV (R) in EPCs and UT7/EpoS1. 
Normalized dose-response curve, calculated from qPCR data obtained at $48 \mathrm{hpi}$ for the different experimental series (B19V in EPCs and UT7/EpoS1). Log B19V DNA as a function of BCV (S) (CMX001) or BCV (R) (CMX029) concentration, expressed as percentage replication compared to control samples. $\mathrm{EC}_{50}$ values derived from this plot are reported in Table 1.

Figure 9. Cell viability, normalized response to BCV-S and BCV-R in EPCs and UT7/EpoS1. Normalized dose-response curve, calculated from CCK8 assay data obtained at $48 \mathrm{hpi}$ for the different experimental series (B19V in EPCs and UT7/EpoS1). Cell viability as a function of BCV (S) (CMX001) or BCV (R) (CMX029) concentration, expressed as percentage value compared to control samples. $\mathrm{CC}_{50}$ values derived from this plot are reported in Table 1. 
Table 1. Effects of tested compounds on B19V replication, cell viability and cell proliferation

\begin{tabular}{|c|c|c|c|c|}
\hline Compound & Cells/moi & $\begin{array}{l}\mathrm{EC}_{50} \\
\text { [C.I.] }\end{array}$ & $\begin{array}{c}\text { CCK8 CC } \text { C }_{50} \\
\text { [C.I.] }\end{array}$ & $\begin{array}{c}\mathrm{SI} \\
\mathrm{CCK} \mathrm{CC}_{50} / \mathrm{EC}_{50}\end{array}$ \\
\hline $\begin{array}{l}\mathrm{BCV}(\mathrm{S}) \\
\mathrm{CMX001}\end{array}$ & EPC $10^{\wedge} 4$ & $\begin{array}{c}14.3 \\
{[11.8-17.3]}\end{array}$ & $\begin{array}{c}93.4 \\
{[68.9-126.6]}\end{array}$ & 6.5 \\
\hline & UT7 10^4 & $\begin{array}{c}0.63 \\
{[0.58-0.68]}\end{array}$ & $\begin{array}{c}59.9 \\
{[52.7-68.1]}\end{array}$ & 95.1 \\
\hline $\begin{array}{l}\text { BCV }(R) \\
\text { CMX029 }\end{array}$ & EPC $10^{\wedge} 4$ & $\begin{array}{c}93.0 \\
{[77.4-111.8]}\end{array}$ & $\begin{array}{c}146.2 \\
{[106.4-200]}\end{array}$ & 1.6 \\
\hline & UT7 10^4 & $\begin{array}{c}54.7 \\
{[42.7-69.9]}\end{array}$ & $\begin{array}{c}72.1 \\
{[62.5-83.1]}\end{array}$ & 1.3 \\
\hline
\end{tabular}

$\mathrm{EC}_{50}$ and $\mathrm{CC}_{50}$ and respective $95 \%$ C.I. values are expressed as $\mu \mathrm{M}$. 
This is the final peer-reviewed accepted manuscript of:

Bua G, Conti I, Manaresi E, Sethna P, Foster S, Bonvicini F, Gallinella G. Antiviral activity of brincidofovir on parvovirus B19. Antiviral Res. 2019 Feb;162: 22-29

The final published version is available online at:

http://dx.doi.org/10.1016/j.antiviral.2018.12.003

Rights / License:

The terms and conditions for the reuse of this version of the manuscript are specified in the publishing policy. For all terms of use and more information see the publisher's website. 